\title{
Past, Present, and Future of Hyperthermic Intraperitoneal Chemotherapy (HIPEC) in Ovarian Cancer
}

\author{
Mona Mishra ${ }^{1}$, Nilanchali Singh ${ }^{2}$, Prafull Ghatage ${ }^{3}$ \\ 1. Obstetrics and Gynecology, Maulana Azad Medical College, New Delhi, IND 2. Obstetrics and Gynecology, All India \\ Institute of Medical Sciences, New Delhi, IND 3. Gynecology and Oncology, Tom Baker Cancer Center, Calgary, CAN
}

Corresponding author: Nilanchali Singh, nilanchalisingh@gmail.com

\begin{abstract}
Hyperthermic intraperitoneal chemotherapy (HIPEC), along with optimal cytoreductive surgery, has been debated to be a viable option for the treatment of advanced epithelial ovarian cancer with peritoneal carcinomatosis. HIPEC is associated with a direct and improved penetration of chemotherapy drugs into the affected tissue and is associated with fewer systemic side effects. There is no standard protocol for the use of HIPEC in advanced ovarian cancer. Hence, there is controversy over the timing, dose, duration, and efficacy of HIPEC. In this review, the history, technique, current evidence, recommendations, and future directions of HIPEC are discussed.
\end{abstract}

Review began 05/19/2021 Review ended 06/01/2021 Published 06/10/2021

(c) Copyright 2021

Mishra et al. This is an open access article distributed under the terms of the Creative Commons Attribution License CC-BY 4.0., which permits unrestricted use, distribution, and reproduction in any medium, provided the original author and source are credited.
Categories: Obstetrics/Gynecology, Oncology

Keywords: hipec, hyperthermic intraperitoneal chemotherapy, ovarian cancer, clinical trials, technique

\section{Introduction And Background}

Ovarian malignancy is the most lethal of all gynecological cancers. The standard of care for ovarian cancer is surgery in early stages and platinum-based chemotherapy followed by interval debulking surgery in advanced cases. With this norm followed, the five-year survival is less than $30 \%$ and recurrence rates are high. Ovarian cancer is known for local spread to the peritoneum, hence, local therapy seems promising. Intraperitoneal (IP) chemotherapy was developed with this idea, and a systemic review found its results promising, with increased survival time and reduced risk of mortality by $12 \%$ with each cycle of intraperitoneal therapy [1]. However, the therapy could not gain popularity due to the higher incidence of adverse events. Lately, increased temperature of the chemotherapy agent used intra-peritoneally is being evaluated for its efficacy in ovarian malignancy. Hyperthermic intraperitoneal chemotherapy, popularly called hyperthermic intraperitoneal chemotherapy (HIPEC), is a technique for delivering a chemotherapeutic agent, in which a heated solution of chemotherapy agent is perfused throughout the peritoneal space (Figure 1). It has been used for the treatment of advanced peritoneal malignancies, including gastrointestinal (colorectal and appendiceal) and advanced ovarian cancers. The aim is to target residual disease after cytoreductive surgery (CRS) by directly acting on the cancer cells present on the peritoneal surface. The blood peritoneal barrier limits systemic absorption of the chemotherapy agent, hence reducing its side effects and toxicity. HIPEC has a controversial role in the management of ovarian cancers. This review deals with the historical aspects, current role, and future perspective of HIPEC. 


\section{Cureus}
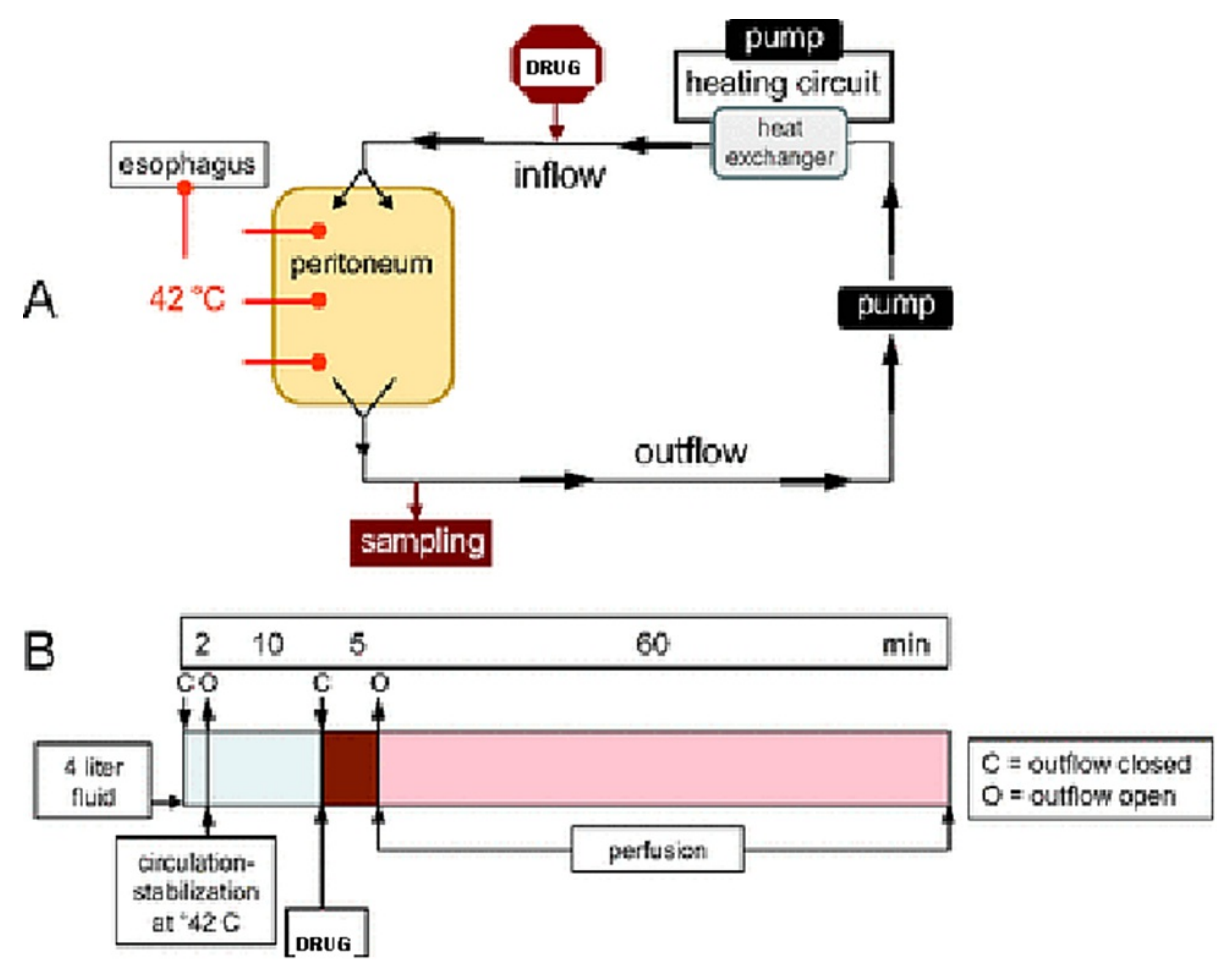

\section{FIGURE 1: Diagrammatic representation of HIPEC}

HIPEC: hyperthermic intraperitoneal chemotherapy

\section{Review}

\section{Rationale of hyperthermia}

Hyperthermia has a multi-fold effect on cancer cells. Firstly, heat encompasses a direct cytotoxic effect on cancer cells by the increased production of lysosomes. Secondly, heat has a synergistic effect with certain anti-mitotic agents (cisplatin, paclitaxel, oxaliplatin, and mitomycin) and potentiates their action [2]. Thirdly, heat improves the penetration of chemotherapy, leading to the increased sensitivity of tumor cells to chemotherapy and interrupting deoxyribonucleic acid (DNA) repair [3-5]. Hyperthermia also helps in reducing resistance to cisplatin by decreasing the mechanisms of cellular resistance [6]. Lastly, it has an immunomodulatory role and improves the immune response against tumor cells by inducing heat shock proteins (HSP), activating antigen-presenting cells, and lymphocyte migration [7].

Although the rising body temperature is associated with significant risks, various methods have been developed for raising the temperature of the intraperitoneal cavity with a minimal increase in the temperature of the rest of the body. During HIPEC, heat is applied loco-regionally and the body's core temperature is controlled. The anesthesia team aids in core temperature control by applying ice packs in the neck and groin regions. Moreover, automated pumps are available, which are specifically designed for temperature-regulated continuous drug delivery and monitoring of the infusion process.

\section{History}

The history of HIPEC is interesting. Egyptian doctors treated tumors with heat around 5000 BC. The Greeks too realized the importance of thermal energy in some form of medical treatment. The most ancient texts of the Law of Moses mention hot springs as having medicinal values. While grazing donkeys, Anah discovered the hot and medicinal springs in the desert, a rare and valuable finding. The techniques in the past have utilized fever-causing microbial extracts or hot water baths for the induction of hyperthermia to treat various ailments [8]. However, both approaches are difficult to monitor. The use of hyperthermia in cancer treatment is first documented by De Kizowitz from France, in 1779. He assessed the effect of fever caused by malaria on malignant tumors. In 1866, Busch in Germany reported the remission of a facial sarcoma in a patient with a high fever due to erysipelas [9]. William Coley, a surgeon from New York Memorial Cancer Hospital, developed the "Coley toxin" in the 1800s, which is a mixture of bacterial culture. It was used to induce hyperthermia in cancer patients. It was the first specialized bacterial antitumor pyrogen [10]. He managed to treat 38 patients with cancers, who had a high-grade fever: 12 patients had complete regression of tumors while 19 patients improved. In 1898, Westermark used total-body hyperthermia with hot baths to treat inoperable cervical cancer and found promising results [11]. 
In the twentieth century, localized heat was used in the form of galvanocautery to treat cervical and uterine cancers [12]. It was found that cancer cells were more sensitive to heat than normal tissues of the body. These findings were reproduced by others as well. Immersion in heated water is another method evaluated. This was used to achieve localized hyperthermia of the limbs or of the entire body. This was used for disseminated tumors.

Luk et al. (1980) investigated hyperthermia with radiotherapy as a treatment modality in patients with advanced cancers not responding to conventional treatment. It was found that hyperthermia achieved by microwave combined with radiotherapy was found to have a higher tumor regression rate as compared to either modality alone. Luk's study was a pilot study in which a temperature average of 42.5 degrees was induced by microwave diathermy to treat superficial cancers. The response of recorded tissue temperatures, either alone or in combination with radiation therapy, was evaluated. The treatment was well-tolerated by patients with only a few side effects [13].

HIPEC was first introduced by John Spratt in 1980 [14]. He treated a pseudomyxoma peritonei patient with intraperitoneal thiotepa followed by hyperthermic intraperitoneal methotrexate. Koga et al. confirmed the role of combined hyperthermia and intraperitoneal chemotherapy in the treatment of implanted peritoneal cancer in rats [15]. He showed that optimal control of peritoneal metastasis was achieved not by heat or chemotherapy alone but by a combination of hyperthermia with chemotherapy. Yonemura and Kanazawa established the role of this treatment in the prevention of gastric cancer peritoneal disease and for the treatment of established disease [16]. The role of HIPEC in improving survival outcomes in peritoneal disease is slowly being established in interval debulking surgery, following neoadjuvant chemotherapy, secondary cytoreductive surgery, and, most recently, in the setting of primary cytoreductive surgery.

\section{Candidates for HIPEC}

Women with primary and recurrent stage IIIc ovarian cancer are most commonly recruited in various observational and interventional studies evaluating the role of HIPEC. Studies performed in ovarian malignancy stages Ic to IIIc have reported better survival outcomes with the use of HIPEC [17]. Evidence of the use of HIPEC in recurrent ovarian cancer is limited to a single trial and a few retrospective studies [18]. There is no consensus regarding the chemotherapeutic drug to be used, the protocol for agent delivery, and postoperative therapy for HIPEC in recurrent ovarian cancer.

\section{Technique}

After resection of all gross disease, the abdominal cavity is initially irrigated with normal saline to remove all particulate matter that may block the outflow circuit and to ensure that there is adequate hemostasis prior to HIPEC delivery. Enteric reconstruction can be carried out prior to or after HIPEC therapy.

Hyperthermia can be generated by various perfusion systems that are available. These systems include closed circuit pumps, which deliver heated chemotherapy drugs through inflow catheters with drainage accomplished via outflow catheters. HIPEC can be performed using two techniques, the open or coliseum technique and the closed technique.

\section{Open Technique}

In the open technique, a big, nonporous synthetic mesh is sewed to the edges of the skin incision, and the abdomen is tented up using retractors. The surgeon manually stirs the perfusate in the abdomen for even distribution and adequate exposure of organs to heated chemotherapy. Inflow and outflow catheters are located on the lateral abdominal wall. The advantages and disadvantages of the open technique are listed in Table 1 .

\section{Advantages of the open technique}

Even distribution of heated chemotherapy throughout the abdominal cavity

\section{Disadvantages of the open technique}

Risk of exposure

Risk of spillage

Time-consuming

Accelerated heat loss

\section{TABLE 1: Advantages and disadvantages of the open technique}




\section{Cureus}

skin is sutured to the frame. The frame is fixed about 3 to 4 inches above the abdomen. This ensures that there is no spillage of the drug. Once sutured, the abdomen is closed with a clear X-ray cassette dressing with a small opening made in the dressing so as to allow for mixing of the drug(s). The technician heats the circulating fluid using D5W to $40^{\circ} \mathrm{C}$ to $42^{\circ} \mathrm{C}$ before injecting the chemotherapy drug.

Closed Technique

In the closed technique, after cytoreduction, the inflow and outflow catheters are introduced into the abdominal cavity through the midline incision. The abdominal incision is sutured ensuring a watertight closure. The abdomen is then instilled with the carrier solution following which perfusion begins. Once the goal temperature of $40^{\circ} \mathrm{C}-42^{\circ} \mathrm{C}$ is reached, the chemotherapy drug is filled in the reservoir and perfused for 30 to 120 minutes. During the procedure, the abdominal wall may be agitated to facilitate even drug distribution throughout the abdominal cavity. After the perfusion cycle is complete, the chemotherapy drug is drained through the outflow catheter and the abdomen is then irrigated with normal saline. The advantages and disadvantages of the closed technique are mentioned in Table 2.

\section{Advantages of the closed technique}

Minimal heat loss

Easy achievement of intraperitoneal goal temperature

Reduced chance of spillage and exposure to chemotherapy drugs

Less time consuming

The theoretical benefit of improved drug penetration

\section{Disadvantages of the closed technique}

Unequal intra-abdominal distribution of chemotherapy drugs

Higher concentration of drug in the blood, leading to myelosuppression

\section{TABLE 2: Advantages and disadvantages of the closed technique}

\section{Chemotherapy drugs used for HIPEC}

An ideal chemotherapy drug to be used for HIPEC should be cell-cycle non-specific, water-soluble, having a synergistic effect with heat, with a high molecular weight and proven cytotoxic effect. There has been no consensus in terms of the choice of chemotherapy drug, its dosage, dwell time, goal temperature, and duration of perfusion. These parameters vary widely across various studies conducted until now as shown in Table 3. 


\section{Cureus}

\begin{tabular}{|c|c|c|c|c|}
\hline Study & Design & Inclusion criteria & Drugs & Results \\
\hline $\begin{array}{l}\operatorname{Lim} \\
2017 \text { [20] }\end{array}$ & $\begin{array}{l}\text { Randomized controlled } \\
\text { trial: HIPEC+ } \\
\text { cytoreductive surgery } \\
\text { (CRS) + systemic } \\
\text { chemotherapy }(n=92) \text {, } \\
\text { CRS + systemic } \\
\text { chemotherapy }(n=92)\end{array}$ & $\begin{array}{l}\text { Primary ovarian cancer } \\
\text { stages } 3 \text { and } 4\end{array}$ & $\begin{array}{l}\text { Cisplatın } / 5 \mathrm{mg} / \mathrm{m} 2,90 \\
\min \text { at } 41.5^{\circ} \mathrm{C}\end{array}$ & $\begin{array}{l}\text { 5-year progression-free survival ( } p= \\
\text { 0.569): HIPEC: } 20.9 \% \text {, Control: } 16 \% \text {; } \\
5 \text {-year overall survival }(p=0.574) \text { : } \\
\text { HIPEC: } 51 \% \text {, Control: } 49.4 \%\end{array}$ \\
\hline $\begin{array}{l}\text { Van Driel } \\
2018 \text { [21] }\end{array}$ & $\begin{array}{l}\text { Multicentric randomized } \\
\text { controlled trial: CRS + } \\
\text { HIPEC }(n=122), \text { CRS } \\
\text { alone }(n=123)\end{array}$ & $\begin{array}{l}\text { Stage III ovarian cancer } \\
\text { patients who have received } \\
\text { neoadjuvant chemotherapy } \\
\text { with carboplatin and } \\
\text { paclitaxel with stable } \\
\text { disease after } 3 \text { cycles }\end{array}$ & $\begin{array}{l}\text { Cisplatin } 100 \mathrm{mg} / \mathrm{m} 2 \text {, } \\
90 \mathrm{~min} \text { at } 40^{\circ} \mathrm{C}\end{array}$ & $\begin{array}{l}\text { Progression[Ns1]-free survival: } \\
\text { HIPEC: } 14.2 \text { months, Control: } 10.7 \\
\text { months; Median overall survival: } \\
\text { HIPEC: } 45.7 \text { months, Control: } 33.9 \\
\text { months Adverse events of grade } 3 \\
\text { and } 4: 25 \% \text { and } 27 \%\end{array}$ \\
\hline $\begin{array}{l}\text { Ansalonı } \\
\text { et al. } \\
2012 \text { [22] }\end{array}$ & $\begin{array}{l}\text { Open prospective phase } 2 \\
\text { study }\end{array}$ & $\begin{array}{l}\text { Primary or recurrent } \\
\text { peritoneal carcinomatosis } \\
\text { with ovarian cancer; } \\
\text { Primary }(n=9), \text { Recurrent } \\
(n=30)\end{array}$ & $\begin{array}{l}\text { Cisplatin } 100 \mathrm{mg} / \mathrm{m} 2 \text {, } \\
\text { Paclitaxel } 175 \mathrm{mg} / \mathrm{m} 2 \text {, } \\
\text { Doxorubicin } 35 \mathrm{mg} / \mathrm{m} 2 \text {, } \\
90 \text { min at } 41.5^{\circ} \mathrm{C}, 66 \% \\
\text { received cisplatin + } \\
\text { doxorubicin. }\end{array}$ & $\begin{array}{l}\text { Recurrence rate } 59 \% \text {; Mean } \\
\text { recurrence time } 14.4 \text { months; Mean } \\
\text { hospital stay } 23.8 \text { days }\end{array}$ \\
\hline
\end{tabular}

\section{TABLE 3: Studies describing the role of HIPEC in primary ovarian cancer}

HIPEC: hyperthermic intraperitoneal chemotherapy

In general, cisplatin is the most commonly used chemotherapy drug used for HIPEC in gynecological malignancies and is recommended by the National Comprehensive Cancer Network (NCCN) guidelines. Other commonly used drugs in HIPEC include paclitaxel, liposomal doxorubicin, either alone or in various combinations. In the setting of primary ovarian cancer, Lim et al. and Van Driel described the use of intraperitoneal cisplatin while Ansaloni et al. used intraperitoneal cisplatin, paclitaxel, and doxorubicin in doses described in Table 3 [20-22]. There has been no consensus in terms of the ideal chemotherapy drug regimen in women receiving HIPEC for the treatment of recurrent ovarian cancer. Fagotti described the use of oxaliplatin while Bakrin et al. used cisplatin alone or along with mitomycin C or doxorubicin [17-18]. Spiliotis et al. used cisplatin and paclitaxel in platinum-sensitive women while doxorubicin and paclitaxel or mitomycin C was given to platinum-resistant women [23]. Large randomized controlled trials are needed in the future to address this. Table 4 and Table 5 show various chemotherapeutic agents used in HIPEC and their mean peak peritoneal activity, respectively. 


\section{Cureus}

\begin{tabular}{|ll}
\hline Drug & Dosage \\
\hline Cisplatin & $50-75 \mathrm{mg} / \mathrm{m} 2$ \\
Doxorubicin & $30-75 \mathrm{mg} / \mathrm{m} 2$ \\
Gemcitabine & $1000 \mathrm{mg} / \mathrm{m} 2$ \\
Paclitaxel & $60-175 \mathrm{mg} / \mathrm{m} 2$ \\
Oxaliplatin & $360-480 \mathrm{mg} / \mathrm{m} 2$ \\
Caelyx & $20-50 \mathrm{mg} / \mathrm{m} 2$ \\
5FU & $600 \mathrm{mg} / \mathrm{m} 2$ \\
Docetaxel & $40-150 \mathrm{mg} / 2$ \\
Carboplatin & AUC $5-6$ \\
\hline
\end{tabular}

\section{TABLE 4: Drugs used for HIPEC and their dosage}

HIPEC: hyperthermic intraperitoneal chemotherapy; AUC: area under the curve

\begin{tabular}{|l|l|}
\hline \hline Carboplatin & 18 \\
\hline Cisplatin & 20 \\
5FU & 298 \\
Paclitaxel & 1000 \\
Doxorubicin & 494 \\
Mephalan & 94 \\
Caelyx & $600-1000$ \\
Gemcitabine & $500-800$ \\
\hline TABLE 5: Mean peak peritoneal cavity: plasma concentration ratio of various chemotherapy \\
\hline agents used in HIPEC
\end{tabular}

\section{Timing of HIPEC}

Intraperitoneal chemotherapy is usually performed immediately after cytoreduction. There is uncertainly on whether the complications are increased if done after any gastrointestinal anastomosis. At our center, HIPEC is preferably performed just prior to closure (after bowel anastomosis, etc). Concerns about the inconveniences of delivery and toxicities associated with postoperative intraperitoneal chemotherapy motivated researchers to work out whether HIPEC could improve safety and quality of life.

\section{Temperature}

The synergistic effect of hyperthermia and intraperitoneal chemotherapy is observed from a temperature of $39^{\circ} \mathrm{C}$ and thereafter increases linearly. However, bowel tissue tolerance to temperature limits the upper limit of heat administered intraperitoneally. A study conducted by Shimizu et al. found that heat administered intra-abdominally in rats was safe at a temperature of $39^{\circ} \mathrm{C}$. However, the application of heat at a temperature of $46^{\circ} \mathrm{C}$ or $45^{\circ} \mathrm{C}$ leads to a mortality of $100 \%$ and $90 \%$, respectively. Also, $100 \%$ survival was found at $44^{\circ} \mathrm{C}$ [24]. Retrospective studies in humans show that an intra-abdominal temperature above $42^{\circ} \mathrm{C}$ is associated with a higher complication rate [25]. Keeping these data in mind, most surgical oncologists have reached a general consensus of $41^{\circ} \mathrm{C}-43^{\circ} \mathrm{C}$ as the desired level of intra-abdominal hyperthermia.

\section{Duration}


The duration of HIPEC varies from 30 minutes to 120 minutes depending on the institutional protocol and other factors like the pharmacokinetics of chemotherapy drugs, patients' cell count, and renal function.

\section{Role of HIPEC in primary ovarian cancer}

The role of HIPEC in the management of primary ovarian carcinoma is still debatable. Most of the studies have not shown any benefit. However, there are a few studies that have shown good results with HIPEC in primary ovarian cancer. Ansaloni et al. (2012) conducted a prospective phase 2 study recruiting 39 patients with primary or recurrent peritoneal carcinomatosis. Seventy-seven percent (77\%) of patients had recurrent carcinomatosis and $23 \%$ had a primary tumor. Cytoreductive surgery was performed in these patients after which HIPEC was performed. The procedure was performed for 90 minutes, with an intraperitoneal temperature of $41.5^{\circ} \mathrm{C}$. Fifty-nine percent (59\%) of patients had recurrence with the mean recurrence time being 14.4 months [22].

Lim et al. in 2017 conducted a randomized controlled trial in women with stages 3 and 4 primary ovarian cancer. There was no significant difference found in progression-free survival (PFS) in the HIPEC versus control groups ( $43.2 \%$ vs. $43.5 \%$ at 2 years and $20.9 \%$ vs. $16.0 \%$ at 5 years; $P=0.569)$. Five-year OS was also found to be similar in both groups [20].

Van Driel et al. conducted a multicentric, prospective randomized controlled trial in women with stage 3 ovarian cancer who had stable disease after receiving three cycles of neoadjuvant chemotherapy. It was a landmark trial in which 245 patients, who underwent interval cytoreductive surgery (CRS) with or without HIPEC, were recruited. A total of 122 patients were randomly assigned to receive intraperitoneal cisplatin $\left(100 \mathrm{mg} / \mathrm{m}^{2}\right)$ after an intra-peritoneal temperature of $40^{\circ} \mathrm{C}$ was achieved with heated saline. One-hundred twenty-three (123) women underwent CRS without HIPEC. Patients received an additional three cycles of adjuvant chemotherapy. The median overall survival rate was 33.9 months and 45.7 months in the surgery and surgery with HIPEC groups, respectively. The median recurrence-free survival rate was 10.7 months in the surgery group and 14.2 months in the surgery with HIPEC group. Grades 3 and 4 toxicities were similar in both groups ( $25 \%$ vs $27 \%$ in the surgery and surgery with HIPEC groups, respectively). The drawbacks of this study include the exclusion of stage 4 ovarian cancer [21].

Forty (40) patients with advanced ovarian malignancy, who were planned for upfront cytoreductive surgery along with HIPEC, were enrolled in a phase II, non-randomized, single-arm study. Patients received adjuvant chemotherapy with bevacizumab after surgery. Complete cytoreduction was achieved in all the cases. Early complications were observed in 23 patients, which included hematological toxicity, pleural effusion requiring a drain, relaparotomy for hemorrhage, and bowel anastomosis dehiscence. Eight patients had major complications (pleural effusion with drain and bowel anastomosis dehiscence). Overall, the data suggested that the safety of HIPEC in the upfront treatment of advanced ovarian cancer is reasonable [26]. The major complications reported in this study were pleural effusion requiring a drain in five patients and bowel anastomosis dehiscence in three patients. The reported late complications were mild and related to kidney failure. No postoperative death was reported in the series.

In a recent trial from China, survival outcomes were compared between primary cytoreductive surgery (PCS) with HIPEC versus PCS alone for patients with stage III epithelial ovarian cancer. Four-hundred twenty-five (425; 72.8\%) underwent PCS with HIPEC and 159 (27.2\%) underwent PCS alone. The median survival time was 49.8 (95\%CI, 45.2-60.2) months for patients undergoing PCS with HIPEC and 34.0 (95\%CI, 28.9-41.5) months for patients undergoing PCS alone, and the three-year overall survival rate was $60.3 \%$ (95\%CI, 55.3\%-65.0\%) for patients undergoing PCS with HIPEC and 49.5\% (95\%CI, 41.0\%-57.4\%) for patients undergoing PCS alone. Subgroup analysis was further done in the complete and incomplete surgery subgroups. Patients in the PCS with HIPEC group had significantly better survival than those in the PCS group, except for the three-year overall survival rate in the incomplete subgroup. Among those who underwent complete surgical procedures and comparing those who received PCS with HIPEC vs those who received PCS alone, the median survival time and the three-year overall survival rate were better in the HIPEC group ( $\mathrm{P}=.04)$. In this study, the PCS with HIPEC treatment approach was associated with better long-term survival [27].

A randomized phase 3 trial showed a significant benefit in recurrence-free and overall survival when HIPEC was added to interval cytoreductive surgery (CRS) in patients who were not eligible for primary surgery because of the extent of their disease (OVHIPEC trial; NCT00426257). The trial showed no important differences in toxicity or patient-reported outcomes between the study groups. The extent of surgery and the number of bowel resections were also similar between the two study groups, and the effect of HIPEC was homogeneous across the levels of predefined and post hoc subgroups. Nevertheless, the design and results of the OVHIPEC trial were critically assessed, and this resembles the reluctance to adopt the positive results of earlier intraperitoneal chemotherapy studies [28].

\section{Role of HIPEC in recurrent ovarian cancer}

There is no clear consensus as to the usefulness and the protocol most suitable for HIPEC in women with recurrent ovarian cancer. In 2012, in a case-control study conducted by Fagotti et al., performing HIPEC led 
to a significant reduction in secondary recurrence and mortality of women having recurrent platinumsensitive ovarian cancer [17].

In a retrospective multicentric study of recurrent or persistent ovarian cancer $(n=246)$, treated by cytoreductive surgery and HIPEC in two French centers, Bakrin et al. (2012) found no significant difference in overall median survival rate in platinum-resistant and platinum-sensitive disease (48 months in platinum-resistant disease and 52 months in platinum-sensitive disease, respectively; $p=0.568$ ) [18]. In another retrospective case-control study conducted by Le Brun (2014) recruiting women with first ovarian cancer relapse, significantly improved overall survival was observed in women receiving CRS followed by HIPEC [29].

A case-control study conducted by Safra et al. (2014) in women with recurrent epithelial ovarian cancer also suggested significant improvement in five-year survival and progression-free survival in women undergoing surgery with HIPEC as compared to those receiving systemic chemotherapy alone. Treatment outcome according to the patients' breast cancer gene (BRCA) status was also compared. Fifty-one point two percent (51.2\%) women in controls and 51.9\% women in the HIPEC group were BRCA gene mutation carriers. BRCA gene mutation carriers were also found to have significantly improved survival on adding HIPEC after CRS (in BRCA gene mutation carriers, progression-free survival was 20.9 months in the HIPEC group and 12.6 months in the chemotherapy alone group, respectively; $\mathrm{p}=0.048$ ) [30]. An observational study by Classe and Petrillo also showed favorable survival rates in women with recurrent ovarian cancer receiving CRS followed by HIPEC [31-32].

In 2015, Spiliotis et al. conducted the first randomized controlled trial recruiting 120 women with stages IIIc and IV disease who had recurrence after initial treatment with debulking surgery followed by systemic chemotherapy. Group A comprising 60 women was treated with secondary debulking surgery followed by HIPEC and systemic chemotherapy. Thirty-four (34) patients were platinum-sensitive with 26 who were platinum-resistant. Intraperitoneal cisplatin $100 \mathrm{mg} / \mathrm{m} 2$ and paclitaxel $175 \mathrm{mg} / \mathrm{m} 2$ was administered for 60 minutes at $42.5^{\circ} \mathrm{C}$ in women with platinum-sensitive disease. Doxorubicin $35 \mathrm{mg} / \mathrm{m} 2$ and either paclitaxel $175 \mathrm{mg} / \mathrm{m} 2$ or mitomycin $15 \mathrm{mg} / \mathrm{m} 2$ was delivered for 60 minutes at $42.5^{\circ} \mathrm{C}$. In 40 women, the open technique was used while in 20 women, the closed technique was used. Women in Group B underwent debulking surgery followed by systemic chemotherapy alone. The mean overall survival rate was found to be significantly higher in group A compared to group B (26.7 versus 13.4 months; $\mathrm{P}<0.006)$. The three-year survival rate was $75 \%$ in group A compared to $18 \%$ in group B $(\mathrm{P}<0.01)$. In platinum-sensitive disease, survival was significantly higher in the HIPEC group compared to the non-HIPEC group (26.8 versus 16.2 months; $\mathrm{P}=0.035)$. In platinum-resistant disease, no significant difference was observed in survival rate in the HIPEC group and the non-HIPEC group (26.6 months versus 10.2 months). Survival was 30.9 months in women who received HIPEC with CC-0. Survival at CC-1 and CC-2 in the HIPEC group was 23.9 months and 12.1 months, respectively. These were statistically different when compared to the non-HIPEC group, in which survival was 16.1 months with CC-0, 11 months with CC-1, and 6.7 months with CC-2(P=0.02) [22].

However, Baiocchi et al. in a retrospective observational study found no significant improvement in survival rate with the addition of HIPEC to secondary cytoreductive surgery. HIPEC was associated with a significantly higher grade III and IV morbidity [33].

Gynecologic Oncology Group-0213 (GOG-0213) is an international, open-label, randomized phase 3 trial in women with platinum-sensitive ovarian cancer in which they showed that secondary cytoreduction did not improve OS. However, this trial has some pitfalls like the compromise of the prespecified stratification variable [34]. In this trial, there were no defined patient eligibility criteria for surgery, and eligibility was based on the surgeon's preference. There was a lack of uniformity in selection criteria or in the methoddefined surgical technique across the various participating centers. The only requirements for GOG-0213 enrollment were platinum-sensitive recurrent ovarian cancer with the possibility of achieving a complete gross resection (CGR) and good medical condition, with acceptable kidney, liver, and bone marrow function, as well as a GOG performance status score of $0-2$. The decision to perform surgery was at the surgeon's discretion. Their data also lacked information on the extent of residual disease after primary debulking surgery and the site of recurrence in some patients. Ascites was mentioned as an exclusion criterion, but it was not further specified if any ascites or a threshold of a certain amount of ascites was exclusive and how much ascites a patient had at diagnosis. To overcome these pitfalls, the DESKTOP (Descriptive Evaluation of preoperative Selection KriTeria for Operability) I trial was planned.

The DESKTOP I was a trial that evaluated a score for the prediction of complete cytoreduction in recurrent ovarian cancer. Resectability at recurrent cancer was improved if three factors, i.e. complete resection at first surgery, good performance status, and absence of ascites, were present [35]. The DESKTOP II trial verified this hypothesis prospectively in a multicenter setting [36]. The DESKTOP III trial investigated the role of surgery in recurrent platinum-sensitive ovarian cancer. A total of 407 patients with recurrent ovarian cancer and a first relapse after a six-month or longer platinum-free interval were randomized to the surgery with adjuvant chemotherapy $(n=206)$ or only chemotherapy without surgery $(n=201)$ groups. This was a superiority trial, with overall survival (OS) as the primary endpoint. Median OS in the intent-to-treat population was 53.7 months with and 46.0 months without surgery (hazard ratio 0.75 , $95 \%$ confidence interval $0.58-0.96 ; \mathrm{P}=.02$ ). Median PFS was 18.4 months with surgery and 14.0 months without (hazard ratio 


\section{Cureus}

$0.66,95 \%$ confidence interval $0.54-0.82 ; \mathrm{P}<.001$ ). DESKTOP III is the first prospectively randomized trial showing an OS benefit of debulking surgery in recurrent ovarian cancer. SOC-3 (Surgery and Niraparib in Secondary Recurrent Ovarian Cancer) is an ongoing multicenter, randomized controlled, phase II trial of secondary cytoreduction followed by chemotherapy and niraparib (PARP-inhibitor) maintenance versus chemotherapy and niraparib maintenance in patients with platinum-sensitive, second relapsed ovarian malignancy. With the above-mentioned completed trials, the role of secondary cytoreduction is well-proven. The addition of HIPEC with secondary cytoreduction needs further validation [37].

Various trials are ongoing in this field including the HORSE (Chemotherapy (HIPEC) in Ovarian Cancer Recurrence) and CHIPOR (Hyperthermic Intra-Peritoneal Chemotherapy (HIPEC) in Relapse Ovarian Cancer Treatment) trials [38-39]. The HORSE trial was a multicentric randomized controlled trial in which progression-free survival will be compared between women having first ovarian cancer recurrence, receiving surgery plus HIPEC versus surgery alone [38]. Similarly, in the CHIPOR trial, 444 patients with ovarian cancer recurrence were recruited and randomized to either undergo surgery with HIPEC or surgery alone [39]. Table 6 describes the role of HIPEC in recurrent ovarian cancer. 


\section{Cureus}

\begin{tabular}{|c|c|c|c|c|}
\hline Study & Design & Inclusion criteria & Drugs & Results \\
\hline $\begin{array}{l}\text { Fagotti } \\
2012[17]\end{array}$ & $\begin{array}{l}\text { Case-control study: } \\
30 \text { cases CRS + } \\
\text { HIPEC, } 37 \text { controls } \\
\text { CRS alone }\end{array}$ & $\begin{array}{l}\text { Platinum-sensitive } \\
\text { recurrent ovarian } \\
\text { cancer }\end{array}$ & $\begin{array}{l}\text { Oxaliplatin } 460 \mathrm{mg} / \mathrm{m} 2,41.5^{\circ} \mathrm{C} \text { for } \\
30 \mathrm{~min} \text {, closed technique }\end{array}$ & $\begin{array}{l}\text { Secondary recurrence } 66.6 \% \text { in } \\
\text { cases, } 100 \% \text { in controls } \\
(P=0.001)\end{array}$ \\
\hline $\begin{array}{l}\text { Bakrin } \\
2012[18]\end{array}$ & $\begin{array}{l}\text { Retrospective } \\
\text { multicentric study } \\
(\mathrm{n}=246)\end{array}$ & $\begin{array}{l}\text { Recurrent and } \\
\text { persistant ovarian } \\
\text { cancer treated with } \\
\text { optimal CRS + HIPEC; } \\
\text { Platinum-resistant } \\
\text { persistant }(n=62) ; \\
\text { Platinum-sensitive } \\
\text { recurrent }(n=184)\end{array}$ & $\begin{array}{l}95.5 \% \text { received cisplatin alone or in } \\
\text { combination with mitomycin } \mathrm{C} \text { or } \\
\text { doxorubicin, } 90 \text { minutes at } 44^{\circ} \mathrm{C}- \\
46^{\circ} \mathrm{C} \text {, open and closed technique }\end{array}$ & $\begin{array}{l}\text { Overall median survival: } 48 \\
\text { months in platinum-resistant and } \\
52 \text { months in platinum-sensitive } \\
(\mathrm{P}=0.568)\end{array}$ \\
\hline $\begin{array}{l}\text { Spiliotis } \\
2015 \text { [23] }\end{array}$ & $\begin{array}{l}\text { Randomized } \\
\text { controlled trial: } \\
\text { Secondary CRS + } \\
\text { HIPEC + systemic } \\
\text { chemotherapy }(n= \\
\text { 60), Secondary CRS } \\
\text { + systemic } \\
\text { chemotherapy }(n=60)\end{array}$ & $\begin{array}{l}\text { Stage Illc \& IV ovarian } \\
\text { cancer with recurrence } \\
\text { after debulking surgery } \\
\text { followed by systemic } \\
\text { chemotherapy }\end{array}$ & $\begin{array}{l}\text { Platinum-sensitive: cisplatin } 100 \\
\mathrm{mg} / \mathrm{m} 2 \text { + paclitaxel } 175 \mathrm{mg} / \mathrm{m} 2 ; \\
\text { Platinum-resistant: doxorubicin } 35 \\
\mathrm{mg} / \mathrm{m} 2 \text { + paclitaxel } 175 \mathrm{mg} / \mathrm{m} 2 \text { or } \\
\text { mitomycin } 15 \mathrm{mg} / \mathrm{m} 260 \mathrm{~min} \text { at } \\
425^{\circ} \mathrm{C} \text {; Open technique }(\mathrm{n}=40) \text {, } \\
\text { Closed technique }(\mathrm{n}=20)\end{array}$ & $\begin{array}{l}\text { Mean overall survival: HIPEC: } \\
26.7 \text { months, No HIPEC: } 13.4 \\
\text { months }(P<0.006)\end{array}$ \\
\hline $\begin{array}{l}\text { Le Brun } \\
2014 \text { [29] }\end{array}$ & $\begin{array}{l}\text { Retrospective case- } \\
\text { control study: CRS + } \\
\text { HIPEC ( } n=23) \text {, CRS } \\
\text { alone }(n=19)\end{array}$ & $\begin{array}{l}\text { Women with first } \\
\text { ovarian cancer relapse } \\
\text { receiving second-line } \\
\text { chemotherapy followed } \\
\text { by CRS }\end{array}$ & $\begin{array}{l}\text { Cisplatin }(n=16): 16 \mathrm{mg} / \mathrm{m} 2 \text {, } \\
\text { eloxatin }(n=6): 6 \mathrm{mg} / \mathrm{m} 2 \text {, mitomycin } \\
C(n=1): 1 \mathrm{mg} / \mathrm{m} 2,42^{\circ} \mathrm{C} \text { for } 1 \text { hour } \\
\text { for cisplatin and } 30 \mathrm{~min} \text { for eloxatin } \\
\text { and mitomycin C. }\end{array}$ & $\begin{array}{l}\text { 4-year overall survival: CRS + } \\
\text { HIPEC: } 75.6 \% \text {, CRS alone: } 19.4 \\
\%(P=0.013)\end{array}$ \\
\hline 2014 [30] & $\begin{array}{l}\text { Case-control study: } \\
\text { CRS+HIPEC }(n=27) \text {, } \\
\text { systemic } \\
\text { chemotherapy alone } \\
(n=84)\end{array}$ & $\begin{array}{l}\text { Recurrent epithelial } \\
\text { ovarian cancer who } \\
\text { underwent BRCA gene } \\
\text { mutation testing }\end{array}$ & $\begin{array}{l}\text { Cisplatin } 50 \mathrm{mg} / \mathrm{m} 2 \text { and doxorubicin } \\
15 \mathrm{mg} / \mathrm{m} 2, \text { Paclitaxel } 60 \mathrm{mg} / \mathrm{m} 2 \text { and } \\
\text { carboplatin, Cisplatin } 25 \mathrm{mg} / 1 / \mathrm{m} 2 \\
\text { and mitomycin-C } 3.3 \mathrm{mg} / 1 / \mathrm{m} 2120 \\
\text { min at } 42.5^{\circ} \mathrm{C}\end{array}$ & $\begin{array}{l}\text { Median progression-free survival } \\
\text { rate: HIPEC: } 15 \text { months systemic } \\
\text { chemotherapy: } 6 \text { months } \\
(P=0.001) .5 \text {-year survival rate } \\
79 \% \text { in CRS + HIPEC, } 45 \% \text { in } \\
\text { systemic chemotherapy } \\
(P=0.016)\end{array}$ \\
\hline $\begin{array}{l}\text { Baiocchi } \\
2015 \text { [33] }\end{array}$ & $\begin{array}{l}\text { Retrospective } \\
\text { observational study: } \\
\text { Secondary } \\
\text { cytoreduction alone } \\
(n=50), \text { Secondary } \\
\text { cytoreduction + } \\
\text { HIPEC }(n=29)\end{array}$ & $\begin{array}{l}\text { Platinum-sensitive } \\
\text { recurrent ovarian } \\
\text { cancer undergoing } \\
\text { secondary } \\
\text { cytoreduction }\end{array}$ & $\begin{array}{l}\text { Mitomycin C }(10 \mathrm{mg} / \mathrm{m} 2) \text { and } \\
\text { cisplatin }(50 \mathrm{mg} / \mathrm{m} 2) \text {, Cisplatin }(50 \\
\mathrm{mg} / \mathrm{m} 2) \text { and doxorubicin }(\mathrm{n}=8) \text {, } \\
\text { Cisplatin alone }(50 \mathrm{mg} / \mathrm{m} 2)(\mathrm{n}=3) \text {, } \\
\text { Closed technique } 41^{\circ} \mathrm{C}-42^{\circ} \mathrm{C} \text { for } 90 \\
\text { min }\end{array}$ & $\begin{array}{l}\text { Median overall survival: no } \\
\text { HIPEC: } 59.3 \text { months, secondary } \\
\text { cytoreduction with HIPEC: } 58.3 \\
\text { months ( } P=0.95) \text {; Median } \\
\text { disease-free survival: no HIPEC: } \\
18.6 \text { months, HIPEC + surgery: } \\
15.8 \text { months ( } P=0.82 \text { ) }\end{array}$ \\
\hline
\end{tabular}

\section{TABLE 6: Studies describing the role of HIPEC in recurrent ovarian cancer}

\section{Consensus guidelines}

Due to these contradictory results of HIPEC, most of the guidelines do not recommend HIPEC as first-line therapy. As per ESMO guidelines, HIPEC is not considered a standard of care as first-line treatment and its use should be limited to well-designed RCTs [40]. Vergote et al. also concluded that HIPEC should not be considered as the standard of care or first-line treatment in the management of ovarian cancer [41]. Because of the positive results by Van Driel [20] and other prospective studies, the NCCN recommends HIPEC with cisplatin $(100 \mathrm{mg} / \mathrm{m} 2)$ to be considered as an option following interval debulking surgery (IDS) in women with stage 3 ovarian cancer who responded or had stable disease after three cycles of neoadjuvant chemotherapy (NACT) [42].

\section{Safety of HIPEC in ovarian cancer}

The morbidity of HIPEC, when combined with cytoreduction, is mainly due to surgical complications such as 
anastomotic leaks, intra-abdominal hemorrhage, and sepsis. Toxicities specific to HIPEC are mainly hematological and renal. Transient bone marrow suppression, anemia, leukopenia, and thrombocytopenia are the frequently reported hematological complications. Acute kidney injury is the most common toxicity in patients undergoing HIPEC with cisplatin. Cisplatin-associated nephrotoxicity can be prevented by using nephroprotectants such as sodium thiosulphate although larger studies are needed to determine the choice of and the optimal dose of nephroprotectants. Other adverse effects are specific to the chemotherapy drugs used. Oxaliplatin is associated with bleeding complications. HIPEC with cytoreductive surgery is associated with higher chances of toxicity as compared to cytoreduction alone. However, recent studies have shown that the toxicity rate of HIPEC alone and HIPEC combined with cytoreduction are similar. In the multicentric RCT conducted by Van Driel, the grade 3-4 toxicity rate was similar in both the groups (25\% versus $27 \%$ in cytoreduction alone and cytoreduction with HIPEC, respectively) [20]. In the retrospective study conducted by Bakrin, overall morbidity was $31 \%$ and mortality was $0.5 \%$. Leukopenia, intra-abdominal hemorrhage, and an anastomotic leak occurred in $11.6 \%, 3 \%$, and $2.4 \%$ respectively [18].

\section{ERAS in HIPEC}

Enhanced Recovery After Surgery (ERAS) Society recommendations, 2020, have provided guidelines for ERAS in cytoreductive surgery with and without HIPEC (CRS \pm HIPEC) [43]. It is recommended that preoperative counseling should be indicated routinely to improve quality of life, somatic symptoms, and psychological outcomes. Preoperative nutritional screening by the use of a validated tool and by measuring serum albumin is also recommended. In patients with malnutrition or at risk for malnutrition, nutritional and protein (>1.2 g/kg/day) supplementation (oral>enteral>parenteral) for at least five days and up to 14 days in cases of severe malnutrition is recommended routinely. In these surgical candidates, a combination of at least two antiemetic drugs (ondansetron, dexamethasone, droperidol) should be indicated routinely to prevent postoperative nausea and vomiting. Prophylactic antibiotics within one hour before incision for CRS \pm HIPEC without the need for routine repeated administration should be indicated routinely to prevent surgical site infection. Total intravenous anesthesia as an alternative to inhalation anesthesia could be indicated to prevent postoperative nausea and vomiting. Preoperative mechanical bowel preparation alone for patients undergoing CRS \pm HIPEC including probable colectomy should not be indicated to reduce the incidence of surgical site infection and an anastomotic leak. Preoperative mechanical bowel preparation is indicated with probable rectal resection. Epidural analgesia (T5-T11, low dose of local anesthetic and opioids) for $72 \mathrm{~h}$ after CRS/HIPEC should be indicated routinely to obtain pain relief, spare opioids, and hasten the resumption of bowel function. Limiting postoperative fluid-related weight gain (target: $<3.5 \mathrm{~kg}$ on postoperative day 3 ) is advised.

\section{Future perspectives}

Most ongoing trials are being conducted on women having primary ovarian cancer. Cisplatin is the most commonly used HIPEC drug in these trials followed by paclitaxel. In the HIPECOV trial, women with both primary and recurrent ovarian cancer are being recruited and the efficacy of HIPEC with lobaplatin following CRS will be evaluated. HORSE and CHIPOR are two large trials that are being conducted, recruiting women with recurrent ovarian cancer. In these two trials, women would undergo platinum-based NACT followed by interval debulking surgery followed by HIPEC in the treatment arm [37-38]. Until now there is no standard guidelines with respect to the exact patient population and the histology of ovarian tumor in which HIPEC would prove to be most beneficial. There is, at present, no standardized chemotherapy drug regimen or guidelines on treatment duration and temperature decided for performing HIPEC. These ongoing trials could probably provide answers to these questions, and their results are eagerly awaited.

Other controversial issues are whether HIPEC is effective as an addition to upfront surgery and after surgery for recurrent disease, whether it has better efficacy as compared to adjuvant intraperitoneal chemotherapy, what are the side/adverse effects of hyperthermia on the body, what is the optimal health care setting required to perform HIPEC, and the use of biomarkers for selecting a suitable subset of patients likely to benefit from HIPEC.

Pressurized intraperitoneal aerosol chemotherapy (PIPAC) is a novel technique in which the chemotherapy drug is delivered in an aerosol form inside the abdominal cavity and maintained at high pressure inside the abdominal cavity. The aerosol form leads to even distribution of the drug on the peritoneal surface while the pressure ensures deeper penetration of the drug. During laparoscopy, the chemotherapy drug is delivered from a high-pressure injector $(1500 \mathrm{kPa})$ through a micropump into the abdominal cavity, and after 30 minutes, the drug-aerosol is suctioned out through a suction system [44]. PIPAC and its role is being explored in women with recurrent ovarian cancer with peritoneal metastasis. Women with peritoneal metastasis are candidates for systemic palliative chemotherapy. However, systemic chemotherapy is less effective in peritoneal metastasis due to poor tumor absorption. In such women, intraperitoneal chemotherapy with PIPAC without cytoreductive surgery has been found to be safe and well-tolerated [45]. It allows for improved tumor penetration and intra-abdominal dissemination. In a systematic review conducted by Tempfer et al., the objective tumor response rate was $69 \%$, and the mean overall survival duration was 13.7 months. It was concluded that PIPAC maintained the quality of life and was found feasible safe and effective in women with ovarian cancer and peritoneal carcinomatosis [46]. In a single-arm, phase 1 , nonrandomized study, PIPAC with dose-escalating cisplatin and doxorubicin could safely be applied in 
women with recurrent ovarian cancer [47]. All studies conducted are single-armed studies and large randomized control trials are needed to provide further evidence in favor of this novel technique.

Table 7 summarizes all ongoing trials studying the role of HIPEC in ovarian cancers.

\begin{tabular}{|c|c|c|c|c|c|c|c|c|c|c|}
\hline NCT number & $\begin{array}{l}\text { Trial } \\
\text { acronym }\end{array}$ & Trial title & $\mathbf{n}$ & Indication & Treatment arm & Control arm & $\begin{array}{l}\text { HIPEC } \\
\text { drug }\end{array}$ & $\begin{array}{l}\text { Duration } \\
\text { of trial }\end{array}$ & Country & Outcome \\
\hline NCT01539785 & HORSE & $\begin{array}{l}\text { Surgery plus hyperthermic intra-peritoneal } \\
\text { chemotherapy (HIPEC) versus surgery alone in } \\
\text { patients with platinum-sensitive first recurrence } \\
\text { of ovarian cancer: a prospective randomized } \\
\text { multicenter trial }\end{array}$ & 158 & $\begin{array}{l}\text { Recurrent } \\
\text { ovarian } \\
\text { cancer }\end{array}$ & $\begin{array}{l}\text { CRS with } \\
\text { HIPEC }\end{array}$ & $\begin{array}{l}\text { CRS without } \\
\text { HIPEC }\end{array}$ & $\begin{array}{l}\text { Cisplatin } \\
\text { at } 75 \\
\mathrm{mg} / \mathrm{m}^{2}\end{array}$ & $\begin{array}{l}\text { September } \\
2012\end{array}$ & Rome, Italy & PFI \\
\hline NCT01376752 & CHIPOR & $\begin{array}{l}\text { Hyperthermic intraperitoneal chemotherapy } \\
\text { (HIPEC) in relapsed ovarian cancer treatment }\end{array}$ & 444 & $\begin{array}{l}\text { Recurrent } \\
\text { platinum- } \\
\text { sensitive } \\
\text { ovarian } \\
\text { cancer }\end{array}$ & $\begin{array}{l}\text { Platinum-based } \\
\text { NACT } \times 6 \\
\text { cycles, followed } \\
\text { by CRS with } \\
\text { HIPEC }\end{array}$ & $\begin{array}{l}\text { Platinum-based } \\
\text { NACT } \times 6 \\
\text { cycles, followed } \\
\text { by CRS without } \\
\text { HIPEC }\end{array}$ & $\begin{array}{l}\text { Cisplatin } \\
\text { at } 75 \\
\mathrm{mg} / \mathrm{m}^{2}\end{array}$ & $\begin{array}{l}4 / 2011- \\
4 / 2025\end{array}$ & Belgium/France & os \\
\hline NCT03842982 & CHIPPI & $\begin{array}{l}\text { Hyperthermic intraperitoneal chemotherapy } \\
\text { (HIPEC) in ovarian cancer }\end{array}$ & 432 & $\begin{array}{l}\text { Primary } \\
\text { EOC }\end{array}$ & $\begin{array}{l}\text { CRS or IDS with } \\
\text { HIPEC }\end{array}$ & $\begin{array}{l}\text { CRS or IDS } \\
\text { without HIPEC }\end{array}$ & $\begin{array}{l}\text { Cisplatin } \\
100 \\
\mathrm{mg} / \mathrm{m} 2 \times \\
90 \mathrm{~min}\end{array}$ & $\begin{array}{l}4 / 2019- \\
6 / 2024\end{array}$ & France & DFS \\
\hline NCT02681432 & $\begin{array}{l}\text { HIPEC- } \\
\text { OVA }\end{array}$ & $\begin{array}{l}\text { Hyperthermic intraperitoneal chemotherapy } \\
\text { with paclitaxel in advanced ovarian cancer }\end{array}$ & 60 & $\begin{array}{l}\text { Primary } \\
\text { EOC }\end{array}$ & $\begin{array}{l}\text { CRS with } \\
\text { HIPEC }\end{array}$ & $\begin{array}{l}\text { CRS without } \\
\text { HIPEC }\end{array}$ & $\begin{array}{l}\text { Paclitaxel } \\
175 \\
\mathrm{mg} / \mathrm{m} 2 \times \\
60 \mathrm{~min}\end{array}$ & $\begin{array}{l}1 / 2012- \\
12 / 2019\end{array}$ & Spain & os \\
\hline NCT03371693 & HIPECOV & $\begin{array}{l}\text { Cytoreductive surgery (CRS) plus hyperthermic } \\
\text { intraperitoneal chemotherapy (HIPEC) with } \\
\text { lobaplatin in advanced and recurrent epithelial } \\
\text { ovarian cancer }\end{array}$ & 112 & $\begin{array}{l}\text { Primary and } \\
\text { recurrent } \\
\text { EOC }\end{array}$ & $\begin{array}{l}\text { CRS with } \\
\text { HIPEC }\end{array}$ & $\begin{array}{l}\text { CRS without } \\
\text { HIPEC }\end{array}$ & $\begin{array}{l}\text { Lobaplatin } \\
30 \mathrm{mg} / \mathrm{m} 2 \\
\text { at } 60^{\prime} \mathrm{C}\end{array}$ & $\begin{array}{l}9 / 2017- \\
12 / 2020\end{array}$ & China & os \\
\hline
\end{tabular}

\section{TABLE 7: Ongoing trials on HIPEC}

[38-39], [48-50]

HIPEC: hyperthermic intraperitoneal chemotherapy; CRS: cytoreductive surgery; PFI: progression-free interval; OS: overall survival; NACT: neoadjuvant chemotherapy; DFS: disease-free survival; IDS: interval debulking surgery; EOC: epithelial ovarian cancer

\section{Conclusions}

HIPEC is an alternative to cytoreductive surgery alone and palliative chemotherapy in women with advanced ovarian cancer with extensive peritoneal metastasis. There exists controversy around HIPEC for both primary and recurrent ovarian cancer, and there is a strong need for more randomized controlled trials on this issue to reach some necessary conclusions. There are difficulties in including HIPEC as a standard of care due to the variation and non-standardization of different studies, in design and protocol. Larger, welldesigned trials are, therefore, needed to provide further answers in terms of exact protocol and drug regimen that would be suitable to perform HIPEC. The suitability of candidates for HIPEC is still an enigma, and the results of ongoing trials would hopefully provide further knowledge in this direction. The five-year survival of advanced ovarian cancer is around 50\% and HIPEC could be a game-changer in the optimal management of women with ovarian cancer and peritoneal metastasis, provided further, well-designed studies prove so.

\section{Additional Information}

\section{Disclosures}

Conflicts of interest: In compliance with the ICMJE uniform disclosure form, all authors declare the following: Payment/services info: All authors have declared that no financial support was received from any organization for the submitted work. Financial relationships: All authors have declared that they have no financial relationships at present or within the previous three years with any organizations that might have an interest in the submitted work. Other relationships: All authors have declared that there are no other relationships or activities that could appear to have influenced the submitted work. 


\section{References}

1. Tewari D, Java JJ, Salani R, et al.: Long-term survival advantage and prognostic factors associated with intraperitoneal chemotherapy treatment in advanced ovarian cancer: a Gynecologic Oncology Group study. J Clin Oncol. 2015, 33:1460-6. 10.1200/JCO.2014.55.9898

2. Kusumoto T, Holden SA, Ara G, Teicher BA: Hyperthermia and platinum complexes: time between treatments and synergy in vitro and in vivo. Int J Hyperthermia. 1995, 11:575-86. $10.3109 / 02656739509022491$

3. van de Vaart PJ, van der Vange N, Zoetmulder FA, et al.: Intraperitoneal cisplatin with regional hyperthermia in advanced ovarian cancer: pharmacokinetics and cisplatin-DNA adduct formation in patients and ovarian cancer cell lines. Eur J Cancer. 1998, 34:148-54. 10.1016/s0959-8049(97)00370-5

4. Panteix G, Beaujard A, Garbit F, et al.: Population pharmacokinetics of cisplatin in patients with advanced ovarian cancer during intraperitoneal hyperthermia chemotherapy. Anticancer Res. 2002, 22:1329-36.

5. Ohno S, Siddik ZH, Kido Y, et al.: Thermal enhancement of drug uptake and DNA adducts as a possible mechanism for the effect of sequencing hyperthermia on cisplatin-induced cytotoxicity in L1210 cells. Cancer Chemother Pharmacol. 1994, 34:302-6. 10.1007/BF00686037

6. Hettinga JV, Konings AW, Kampinga HH: Reduction of cellular cisplatin resistance by hyperthermia-a review. Int J Hyperthermia. 1997, 13:439-57. 10.3109/02656739709023545

7. Skitzki JJ, Repasky EA, Evans SS: Hyperthermia as an immunotherapy strategy for cancer . Curr Opin Investig Drugs. 2009, 10:550-8.

8. Braude AI, Beck J, Zalesky M: Febrile response to bacterial pyrogens in leukemia . Blood. 1960, 16:1279-84. 10.1182/blood.V16.3.1279.1279

9. Berliner entomologische Zeitschrift / herausgegeben von dem Entomologischen Vereine in Berlin [Article in German]. Entomologische Verein in Berlin. 1866, 1866:488.

10. Coley WB: The treatment of malignant tumors by repeated inoculations of erysipelas. With a report of ten original cases. 1893. Clin Orthop Relat Res. 1991, 3-1.

11. Westermark F: Uber die Behandlung des ulcerirenden Cervix carcinoma mittels Knonstanter Warme [Article in German]. Zbl Gynak. 1898, 22:1335-7.

12. Regional Chemotherapy. Hyperthermia in cancer treatment. (2016). Accessed: July 11, 2020: https://regionalchemotherapy.com/treatments/hyperthermia-cancer-treatment/.

13. Luk KH, Hulse RM: Hyperthermia in cancer therapy. West J Med. 1980, 132:179-85.

14. Spratt IS, Adcock RA, Muskovin M, et al.: Clinical delivery system for intraperitoneal hyperthermic chemotherapy. Cancer Res. 19801, 40:256-60.

15. Koga S, Hamazoe R, Maeta M, et al.: Treatment of implanted peritoneal cancer in rats by continuous hyperthermic peritoneal perfusion in combination with an anticancer drug. Cancer Res. 1984, 44:1840-2.

16. Fujimura T, Yonemura Y, Muraoka K, et al.: Continuous hyperthermic peritoneal perfusion for the prevention of peritoneal recurrence of gastric cancer: randomized controlled study. World J Surg. 1994, 18:150-5. 10.1007/BF00348209

17. Fagotti A, Costantini B, Petrillo M, et al.: Cytoreductive surgery plus HIPEC in platinum-sensitive recurrent ovarian cancer patients: a case-control study on survival in patients with two year follow-up. Gynecol Oncol. 2012, 127:502-5. 10.1016/j.ygyno.2012.09.020

18. Bakrin N, Cotte E, Golfier F, et al.: Cytoreductive surgery and hyperthermic intraperitoneal chemotherapy (HIPEC) for persistent and recurrent advanced ovarian carcinoma: a multicenter, prospective study of 246 patients. Ann Surg Oncol. 2012, 19:4052-8. 10.1245/s10434-012-2510-4

19. Fong Y, Gamblin TC, Han ES, Lee B, Zager JS: Cancer Regional Therapy. HAI, HIPEC, HILP, ILI, PIPAC and Beyond. Springer Nature, Switzerland;

20. Lim MC, Chang S-J, Yoo HJ, et al.: Randomized trial of hyperthermic intraperitoneal chemotherapy (HIPEC) in women with primary advanced peritoneal, ovarian, and tubal cancer. J Clin Oncol. 2017, 35: 5520. 10.1200/TCO.2017.35.15_suppl.5520

21. van Driel WJ, Koole SN, Sikorska K, et al.: Hyperthermic intraperitoneal chemotherapy in ovarian cancer . N Engl J Med. 2018, 378:230-4. 10.1056/NEJMoa1708618

22. Ansaloni L, Agnoletti V, Amadori A, et al.: Evaluation of extensive cytoreductive surgery and hyperthermic intraperitoneal chemotherapy (HIPEC) in patients with advanced epithelial ovarian cancer. Int J Gynecol Cancer. 2012, 22:778-85. 10.1097/IGC.0b013e31824d836c

23. Spiliotis J, Halkia E, Lianos E, Kalantzi N, Grivas A, Efstathiou E, Giassas S: Cytoreductive surgery and HIPEC in recurrent epithelial ovarian cancer: a prospective randomized phase III study. Ann Surg Oncol. 2015, 22:1570-5. 10.1245/s10434-014-4157-9

24. Shimizu T, Maeta M, Koga S: Influence of local hyperthermia on the healing of small intestinal anastomoses in the rat. Br J Surg. 1991, 78:57-9. 10.1002/bjs.1800780119

25. Jacquet $\mathrm{P}$, Stephens AD, Averbach AM, et al.: Analysis of morbidity and mortality in 60 patients with peritoneal carcinomatosis treated by cytoreductive surgery and heated intraoperative intraperitoneal chemotherapy. Cancer. 1996, 77:2622-9. 10.1002/(SICI)1097-0142(19960615)77:12<2622::AIDCNCR28>3.0.CO;2-T

26. Paris I, Cianci S, Vizzielli G, et al.: Upfront HIPEC and bevacizumab-containing adjuvant chemotherapy in advanced epithelial ovarian cancer. Int J Hyperthermia. 2018, 35:370-4. 10.1080/02656736.2018.1503346

27. Lei Z, Wang Y, Wang J, et al.: Evaluation of cytoreductive surgery with or without hyperthermic intraperitoneal chemotherapy for stage III epithelial ovarian cancer. JAMA Netw Open. 2020, 3:e2013940. 10.1001/jamanetworkopen.2020.13940

28. The Netherlands Cancer Institute. Phase III Randomized clinical trial for stage III epithelial ovarian cancer randomizing between primary cytoreductive surgery with or without hyperthermic intraperitoneal chemotherapy. (2021). Accessed: January 14, 2021: https://clinicaltrials.gov/ct2/show/NCT03772028.

29. Le Brun JF, Campion L, Berton-Rigaud D, et al.: Survival benefit of hyperthermic intraperitoneal chemotherapy for recurrent ovarian cancer: a multi-institutional case control study. Ann Surg Oncol. 2014, 21:3621-7. 10.1245/s10434-014-3693-7 
30. Safra T, Grisaru D, Inbar M, et al.: Cytoreduction surgery with hyperthermic intraperitoneal chemotherapy in recurrent ovarian cancer improves progression-free survival, especially in BRCA-positive patients-a case-control study. J Surg Oncol. 2014, 110:661-5. 10.1002/jso.23688

31. Classe J-M, Glehen O, Decullier E, et al.: Cytoreductive surgery and hyperthermic intraperitoneal chemotherapy for first relapse of ovarian cancer. Anticancer Res. 2015, 35:4997-5005.

32. Petrillo M, De Iaco P, Cianci S, et al.: Long-term survival for platinum-sensitive recurrent ovarian cancer patients treated with secondary cytoreductive surgery plus hyperthermic intraperitoneal chemotherapy (HIPEC). Ann Surg Oncol. 2016, 23:1660-5. 10.1245/s10434-015-5050-x

33. Baiocchi G, Ferreira FO, Mantoan H, et al.: Hyperthermic intraperitoneal chemotherapy after secondary cytoreduction in epithelial ovarian cancer: a single-center comparative analysis. Ann Surg Oncol. 2016, 23:1294-301. 10.1245/s10434-015-4991-4

34. Coleman RL, Brady MF, Herzog TJ, et al.: Bevacizumab and paclitaxel-carboplatin chemotherapy and secondary cytoreduction in recurrent, platinum-sensitive ovarian cancer (NRG Oncology/Gynecologic Oncology Group study GOG-0213): a multicentre, open-label, randomised, phase 3 trial. Lancet Oncol. 2017, 18:779-91. 10.1016/S1470-2045(17)30279-6

35. Harter P, du Bois A, Hahmann M, et al.: Surgery in recurrent ovarian cancer: the Arbeitsgemeinschaft Gynaekologische Onkologie (AGO) DESKTOP OVAR trial. Ann Surg Oncol. 2006, 13:1702-10. 10.1245/s10434-006-9058-0

36. Harter P, Sehouli J, Reuss A, et al.: Prospective validation study of a predictive score for operability of recurrent ovarian cancer: the Multicenter Intergroup Study DESKTOP II. A project of the AGO Kommission OVAR, AGO Study Group, NOGGO, AGO-Austria, and MITO. Int J Gynecol Cancer. 2011, 21:289-95. 10.1097/IGC.0b013e31820aaafd

37. Du Bois A, Sehouli J, Vergote I, et al.: Randomized phase III study to evaluate the impact of secondary cytoreductive surgery in recurrent ovarian cancer: final analysis of AGO DESKTOP III/ENGOT-ov20. J Clin Oncol. 2020, 38:6000. 10.1200/JCO.2020.38.15_suppl.6000

38. Surgery plus hyperthermic intra-peritoneal chemotherapy (HIPEC) versus surgery alone in patients with platinum-sensitive first recurrence of ovarian cancer: a prospective randomized multicenter trial. (2014). https://clinicaltrials.gov/ct2/show/NCT01539785.

39. A phase III randomized study evaluating hyperthermic intra-peritoneal chemotherapy (HIPEC) in the treatment of relapse ovarian cancer. (2020). Accessed: May 20, 2021: https://clinicaltrials.gov/ct2/show/NCT01376752.

40. Colombo N, Sessa C, du Bois A, et al.: ESMO-ESGO consensus conference recommendations on ovarian cancer: pathology and molecular biology, early and advanced stages, borderline tumours and recurrent disease. Ann Oncol. 2019, 30:672-705.

41. Vergote I, Harter P, Chiva L: Is there a role for intraperitoneal chemotherapy, including HIPEC, in the management of ovarian cancer?. J Clin Oncol. 2019, 37:2420-3. 10.1200/JCO.19.00091

42. Armstrong DK, Alvarez RD, Bakkum-Gamez JN, et al.: NCCN Guidelines insights: ovarian cancer, version 1.2019. J Natl Compr Canc Netw. 2019, 17:896-909.

43. Hübner M, Kusamura S, Villeneuve L, et al.: Guidelines for perioperative care in cytoreductive surgery (CRS) with or without hyperthermic IntraPEritoneal chemotherapy (HIPEC): Enhanced recovery after surgery (ERAS ${ }^{\circledR}$ ) society recommendations - part I: preoperative and intraoperative management. Eur J Surg Oncol. 2020, 46:2292-310. 10.1016/j.ejso.2020.07.041

44. Nadiradze G, Horvath P, Sautkin Y, Archid R, Weinreich FJ, Königsrainer A, Reymond MA: Overcoming drug resistance by taking advantage of physical principles: Pressurized Intraperitoneal Aerosol Chemotherapy (PIPAC). Cancers (Basel). 2019, 12:34. 10.3390/cancers12010034

45. Tempfer CB, Winnekendonk G, Solass W, et al.: Pressurized intraperitoneal aerosol chemotherapy in women with recurrent ovarian cancer: a phase 2 study. Gynecol Oncol. 2015, 137:223-8. 10.1016/j.ygyno.2015.02.009

46. Tempfer C, Giger-Pabst U, Hilal Z, Dogan A, Rezniczek GA: Pressurized intraperitoneal aerosol chemotherapy (PIPAC) for peritoneal carcinomatosis: systematic review of clinical and experimental evidence with special emphasis on ovarian cancer. Arch Gynecol Obstet. 2018, 298:243-57. 10.1007/s00404018-4784-7

47. A phase I, single-arm, open-label, three step dose escalation study with intraperitoneal pressurized cisplatin and doxorubicin in recurrent ovarian cancer and peritoneal carcinomatosis. (2018). Accessed: June 3, 2020: https://clinicaltrials.gov/ct2/show/NCT02475772.

48. Phase III randomized clinical trial evaluating hyperthermic intraperitoneal chemotherapy (HIPEC) in ovarian cancer considering two different settings: primary debulking surgery (PDS) and interval debulking surgery (IDS). (2019). Accessed: June 3, 2020: https://clinicaltrials.gov/ct2/show/NCT03842982.

49. Hyperthermic intraperitoneal chemotherapy with paclitaxel for the treatment of patients with recurrent or primary advanced ovarian cancer: a randomised phase 3 study. (2016). Accessed: June 3, 2020: https://clinicaltrials.gov/ct2/show/NCT02681432.

50. A phase III clinical trial of cytoreductive surgery (CRS) plus hyperthermic intraperitoneal chemotherapy (HIPEC) with lobaplatin in advanced and recurrent epithelial ovarian cancer . (2017). Accessed: June 3, 2020: https://clinicaltrials.gov/ct2/show/NCT03371693. 